International
Journal of

\title{
Effect on badminton players by selected exercises of flexibility and co-ordination
}

I PRAMOD KUMAR SAHADEORAO BHALERAO

Received : 27.05.2014; Revised : 05.09.2014; Accepted : 18.09.2014

Author for Correspondence :

\section{PRAMODKUMAR}

SAHASEORAO BHALERAO

Degree College of Physical

Education, H.V.P.M., AMRAVATI

(M.S.) INDIA

\section{aBSTRACT}

The aim of the investigator to find out the effect of selected exercises on flexibility and co-ordination of Badminton players. Badminton has an important place in the world of sports. It has grown enormously in popularity over the last few years. Exercise is very important for the development of co-ordination and flexibility of Badminton players. For that purpose twenty badminton players of Degree College of Physical Education, Amravati were selected as the subjects. The age of the subject was ranging in between 18 to 25 years. Random group design was adopted for the study. The subjects were equally divided into two groups. i.e. experimental and control group. Each group was considered of 10 subjects. The experimental group went through a training programme of selected exercises for a period of six week. The control group engaged with their regular physical activity only. The data was collected before and immediate after completion of 6 weeks training programme by using the Sit and Reach Test Shoulder Elevation Test, Eye Hand Coordination test and Eye Foot Coordination Tool. To find out the significant difference of mean performance of control group and experimental group-t test was applied. To test the hypothesis the level of significance was set at 0.05 level of confidence. The findings of this study revealed that there is a significant improved in the performance of the experimental group after six week training programme but there is no significant improvement to the performance of the control group.

- Key Words : Selected Exercises, Flexibility, Co-ordination

- How to cite this paper : Bhalerao, Pramod kumar Sahadeorao (2014). Effect on badminton players by selected exercises of flexibility and co-ordination. Internat. J. Phy. Edu., 7 (2) : 55-58. 